THE APPROACHING TOTAL ECLIPSE OF THE SUN.

SINCE our last note on this subject, H.M.S. Volage, with the instruments belonging to Mr. Norman Lockyer's party which is to observe, if possible, on the
Dockyard in a few days' time, and no alterations will be made in the arrangements already published.

The accompanying map (Fig. I) shows the possible stations south of the fiord, with the duration of totality at each.

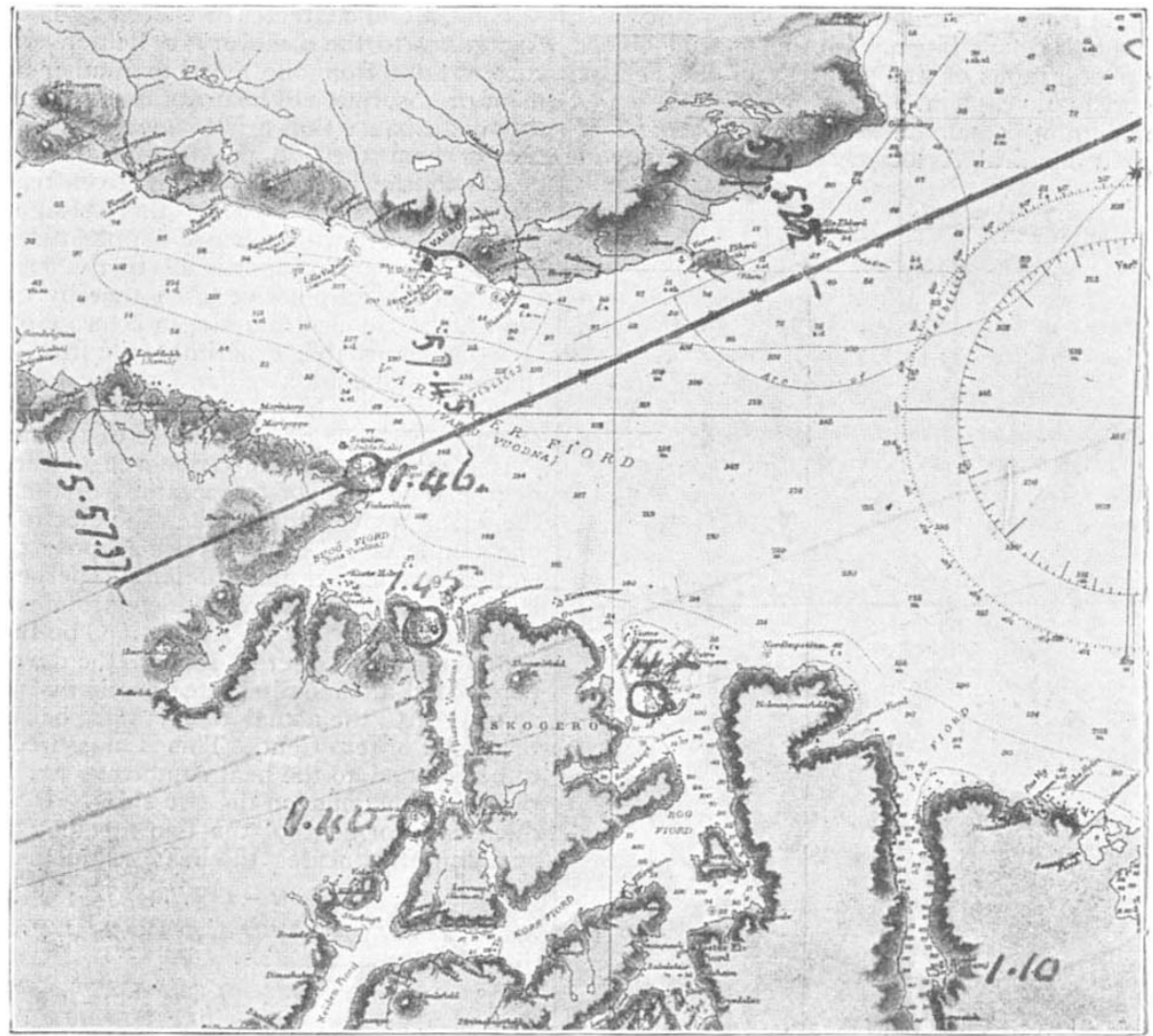

Fig, I. - Duration of Totality South of the Varanger Fiord.

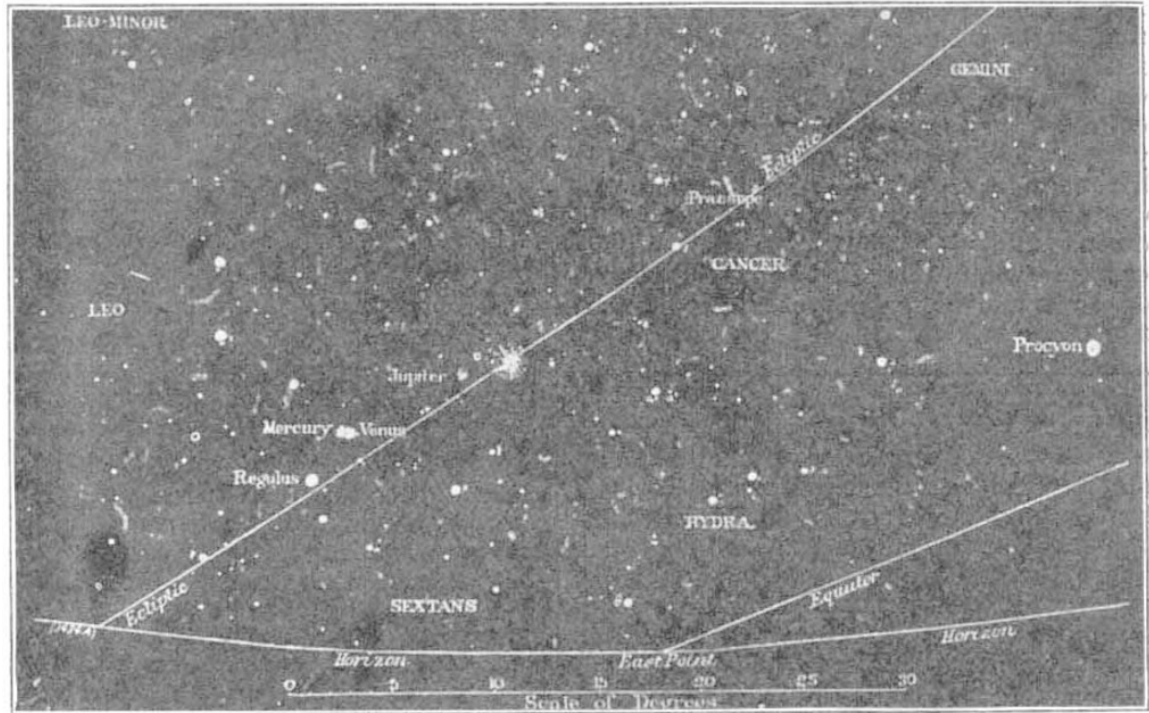

FIG. 2. - Stars and Planets near the Sun at the Time of Totality.

south side of the Varanger fiord, has been detached from the Training Squadron to repair a slight damage. It is expected that she will be able to leave the Portsmouth
It has been announced that all the ships of the Training Squadron will proceed to the neighbourhood"of the Varanger fiord to observe the eclipse.

NO. I 390 , VOL. 54$]$ 
Owing to the offer of Sir George Baden-Powell to take an observing party to Novaya Zemlya in his yacht, it is quite possible that that station may be occupied by English observers as well as by the expeditions sent by the St. Petersburg Academy of Sciences and the Kasan Society of Naturalists.

An expedition from Harvard College Observatory will accompany Prof. Todd to Japan, with the special object of obtaining photographs of the progress of the eclipse with a large prismatic camera.

Mr. Crommelin has communicated to the Journal of the British Astronomical Association a reduced map of

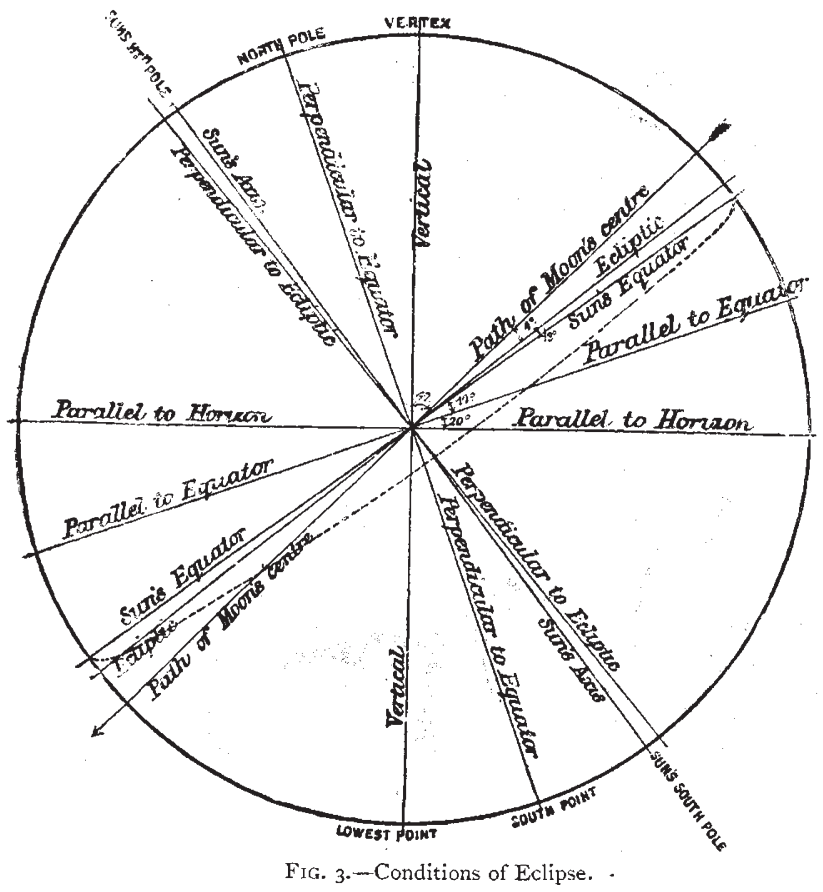

the stars and planets near the sun at the time of totality (Fig. 2), and a diagram showing the relation of the sun's axis and equator, and the path of the moon's centre to the horizon at Vadsö (Fig. 3). These, by the courtesy of Mr. Crommelin, we are enabled to reproduce.

According to Prof. Mohn, the weather chances in Lapland are vastly superior to those in Japan. We are glad also to learn that many lovers of nature are taking advantage of the opportunity of seeing one of the grandest of natural phenomena under the favourable conditions afforded by modern travel, not forgetting that the eclipse takes place in a region of beautiful scenery and in the holiday season of the year.

\section{THE ELECTRICAL RESISTANCE OF ALLOYS.}

$T \mathrm{HE}$ recent researches of Profs. Dewar and Fleming upon the electrical resistance of metals at low temperatures have brought into strong relief the difference between the behaviour of pure metals and of alloys. In the former case the resistance shows every sign of tending to disappear altogether as the absolute zero of temperature is approached, but in the case of alloys this condition of things is widely departed from, even when the admixture consists only of a slight impurity.

Some years ago it occurred to me that the apparent resistance of an alloy might be partly made up of thermoelectric effects, and as a rough illustration I calculated the case of a conductor composed of two metals arranged in alternate laminæ perpendicular to the direction of the NO. I 390, VOL. 54] current. Although a good many difficulties remain untouched, I think that the calculation may perhaps suggest something to those engaged upon the subject. At any rate it affords $\dot{a}$ prior $i$ ground for the supposition that an important distinction may exist between the resistances of pure and alloyed metals.

The general character of the effect is easily explained. According to the discovery of Peltier, when an electric current flows from one metal to another there is development or absorption of heat at the junction. The temperature disturbance thus arising increases until the conduction of heat through the laminæ balances the Peltier effects at the junctions, and it gives rise to a thermoelectromotive force opposing the passage of the current. Inasmuch as the difference of temperature at the alternate junctions is itself proportional to the current, so is also the reverse electromotive force thereby called into play. Now a reverse electromotive force proportional to current is indistingurshable experimentally from a resistance; so that the combination of laminated conductors exhibits a false resistance, having (so far as is known) nothing in common with the real resistance of the metals.

If $e$ be the thermo-electric force of the couple for one degree difference of temperature of the junctions; $t, t^{\prime}$ the actual temperatures; then the electromotive force for one couple is $e\left(t-t^{\prime}\right)$. If we suppose that there are $n$ similar couples per unit of length perpendicular to the lamination, the whole reverse electromotive force per unit of length is $n e\left(t-t^{\prime}\right)$. Again, if $\mathrm{C}$ be the current corresponding to unit of cross-section, the development of heat per second at each alternate junction is per unit of area $273 \times e \times \mathrm{C}$, the actual temperature being in the neighbourhood of zero Cent. This is measured in ergs, and is to be equated to the heat conducted per second towards the cold junctions on the two sides. If $k, k^{\prime}$ be the conductivities for heat of the two metals, $l$ and $l^{\prime}$ the corresponding thicknesses, the heat conducted per second is

$$
\left(t-t^{\prime}\right)\left\{k / l+k^{\prime} \mid l^{\prime}\right\}
$$

or if $l\left(l+l^{\prime}\right)=p, l^{\prime} /\left(l+l^{\prime}\right)=q, l+l^{\prime}=1 / n$, the conducted heat is

$$
n\left(t-t^{\prime}\right)\left\{k / p+k^{\prime} / q\right\} \text {. }
$$

In this expression $p+q=\mathrm{I}$, the symbols $p$ and $q$ denoting the proportional amounts by volume in which the two metals are associated. Thus when a stationary state is reached,

$$
273 \times e \times \mathrm{C}=n\left(t-t^{\prime}\right)\left\{k / p+k^{\prime} / q_{i}^{\prime} .\right.
$$

This determines $\left(t-t^{\prime}\right)$ when $\mathrm{C}$ is given ; and the whole back electromotive force per unit of thickness is $r \mathrm{C}$, where

$$
r=\frac{273 \times e^{2}}{k / p+k^{\prime} / q}
$$

This is the expression for the false resistance per unit of thickness, which, it should specially be noted, is independent of $n$, the number of couples. The number of couples which co-operate is indeed increased by finer lamination, but the efficiency of each is decreased in the same proportion by the readier conduction of heat between the junctions. It is scarcely necessary to point out that the false resistance is called into play only by currents which flow across the laminæ.

In my original calculation the metals chosen for illustration were iron and copper. In this case (Everett's C.G.S. system of units, p. I92) $e=1600$. The conductivities are to be measured in ergs. For iron, $k={ }^{\prime} 164 \times 4^{*} 2 \times 10^{7} ;$ for copper, $k^{\prime}=1.11 \times 4^{\cdot} 2 \times 10^{7}$. Thus, if the metals are in equal volumes $\left(p=q=\frac{1}{2}\right)$,

$$
r=\frac{2 \times 273 \times 1600^{2}}{4 \cdot 2 \times 10^{7} \times 1 \cdot 27}=26 \cdot 2 .
$$

This is the thermo-electric addition to the true specific resistance, and is about $\mathrm{I} \frac{1}{2}$ per cent. of that of copper. Such an addition may seem small; but it should be re. 